\title{
Electron Paramagnetic Resonance Investigation of Nitrite Binding in Myoglobin*
}

\author{
Matthew Bawn ${ }^{1,2}$, Fraser MacMillan ${ }^{1}$ \\ ${ }^{1}$ From the Henry Wellcome Unit for Biological EPR, School of Chemistry, University of East \\ Anglia, Norwich, Norfolk, NR4 7TJ, UK \\ * Running title: EPR of Nitrite Binding in Myoglobin
}

Keywords: hemoglobin myoglobin; spectroscopy; protein chemistry; small molecules; nitrosylation

Background: Myoglobin has been theorized to have a role as a nitrite reductase. Results: $O$-bound nitrite produces a low-spin ferric heme complex, whilst at high $\mathrm{pH}$ a high-spin species is found proposed to be the $N$-bound form. Conclusion: Nitrite may bind to heme in myoglobin via $N$-nitro or $O$-nitrito mode. Significance: The mechanism of any nitrite reduction will depend on its binding to the heme cofactor.

\begin{abstract}
It has been proposed that myoglobin $(\mathrm{Mb})$ may act as a nitrite reductase under hypoxic conditions. Any mechanism describing such activity should take into account the binding geometry of the ligand to the heme. Crystal structures of horse-heart $\mathrm{Mb}$ and human hemoglobin-nitrite complexes suggest that the anion adopts an uncommon $O$-nitrito binding mode. Electron Paramagnetic Resonance (EPR) spectroscopy was employed to investigate the nature of nitrite binding to $\mathrm{Mb}$ at $\mathrm{pH}$ values ranging from 6.5 to 10.8 . Results suggest that for ferric $\mathrm{Mb}$ at low $\mathrm{pH}$, nitrite binds in the $O$-bound nitrito mode resulting in a low-spin (LS) iron center. Further a high-spin (HS) iron center is observed at high $\mathrm{pH}$ in $\mathrm{Mb}$-Nitrite with spectral values different to that of purely $\mathrm{HS}-\mathrm{Mb}$ that is proposed to be due to an $N$-bound nitrite. The yields of these two species were found to be influenced by $\mathrm{pH}$.
\end{abstract}


EPR of Nitrite Binding in Myoglobin

\section{Introduction}

It has been established that many mammalian heme proteins react with various nitrogen oxide species and that these reactions are biologically relevant to mammalian physiology. Recent studies have indicated a role for nitrite as an endocrine storage pool of $\mathrm{NO}^{\bullet}$ that can be bioactivated along the physiological oxygen gradient in order to mediate a number of responses, including hypoxic vasodilatation, (1) cyto-protection following cardiac ischemia/reperfusion and $\mathrm{NO}^{\circ}$-dependant and independent signalling. It is generally believed that nitrite reduction by heme-containing nitrite reductase (NiR) enzymes begins by the ligation of the nitrite anion to the heme iron centre within these proteins. As such a determination of the binding mode adopted by the nitrite anion within the heme protein is an important step in the elucidation of the mechanism of NiR activity. It has been widely accepted for some time that the primary source of nitric oxide within biological tissue is the metabolism of L-arginine by NO ${ }^{\circ}$ synthase (NOS) (2). There is, however, increasing evidence for alternative NOS-independent mechanisms for $\mathrm{NO}^{\circ}$ synthesis. It is also believed that these mechanisms may function in situations where NOSderived $\mathrm{NO}^{\bullet}$ production is impaired $(1,3)$. Inorganic $\mathrm{NO}_{2}$ is an endogenous anion produced by the oxidation of $\mathrm{NO}^{\bullet}$ under aerobic conditions (4). Conversely, the opposite redox reactions yield $\mathrm{NO}^{\circ}$ in acidic conditions from the reduction of $\mathrm{NO}_{2}$. $\mathrm{NO}^{-}$is thought to be generated via deoxyhemoglobin during blood circulation and to have vaso-dilatory properties.

This alternative mechanism for $\mathrm{NO}^{\bullet}$ production may be of particular importance under ischemic conditions since the NOS mechanism is oxygen dependent. As a consequence of the renewed interest in nitrite ligation to $\mathrm{Mb}$, Copeland and Richter-Addo (5) have investigated the crystal structure of horse heart $\mathrm{Mb}$ to analyze how nitrite interacts with the heme center. Although several binding modes are known for nitrite to metals (6), the coordination to hemes (7-9) has nearly always exhibited the common $N$-nitro mode (Fig. 1). The structures of synthetic ironporphyrin compounds with both ferric and ferrous centers $(10,11)$ have also revealed the $N$-nitro mode. In order to determine whether the binding mode of the nitrite anion was directed by the specific amino acid residues within the heme binding pocket Richter-Addo and colleagues performed crystallographic studies on a series of Mb variants (12). They observed that when hydrogen bonding residues were present the $O$-nitrito mode was preferentially adopted by the ligand and when these residues were removed the $N$-nitro mode was more favored. Continuous Wave (cw)-Electron Paramagnetic Resonance (EPR) spectroscopy has been shown to be an 
EPR of Nitrite Binding in Myoglobin

excellent spectroscopic tool for the investigation of the heme-ligand structures in both low spin (LS) and high spin (HS) ferric heme systems (13). These spin-states produce predominantly either rhombic or axial EPR spectra, respectively, the g-values of which provide an indication of the local symmetry within the heme moiety.

To determine affect of hydrogen bonding to the binding mode adopted in ferric $\mathrm{Mb}$ unconstrained from the restrictions imposed by crystallisation, EPR spectroscopy was applied to a series of $\mathrm{Mb}-\mathrm{NO}_{2}$ complexes over a range of $\mathrm{pH}$ values (from 6.5 to 10.8).

\section{EXPERIMENTAL PROCEDURES}

EPR Sample preparation: $\mathrm{Mb}$ samples were made using horse heart $\mathrm{Mb}$, all reagents were purchased from Sigma-Aldrich and used without further purification. $50 \mathrm{mM}$ MES, HEPES, TAPS CHES and CAPS buffers were used to obtain samples of $\mathrm{pH}$ 5.5, 7.5, 8.5, 9.5 and 10.8 respectively. Phosphate buffers were avoided due to the known $\mathrm{pH}$ artifacts associated with freezing (14). Nitrite was added in the form of sodium nitrite to 240 -fold excess. $\mathrm{Na}^{14} \mathrm{NO}_{2}$ was of at least $97 \%$ purity with sulfite and chloride anion concentrations of less than $0.01 \%$ and $0.05 \%$ respectively. For isotope labeling experiments $\mathrm{Na}^{15} \mathrm{NO}_{2}$ contained $98 \% \mathrm{Na}^{15}$ and was $95 \%$ complete product isotope labeled nitrite. Samples were contained in suprasil quartz EPR tubes and stored at $77 \mathrm{~K}$ when not in use.

cw-EPR spectroscopy was performed using a Bruker eleXsys E500 X-band (nominally 9.4 $\mathrm{GHz}$ ) spectrometer fitted fitted with a ER 4122 SHQ cavity and an Oxford Instruments (Oxford Instruments, Oxfordshire, UK) ESR 900 continuous flow helium cryostat. Spectra were recorded at $10 \mathrm{~K}$ using a microwave (mw) power of $0.1 \mathrm{~mW}$ a $100 \mathrm{KHz}$ modulation frequency and a modulation amplitude of $5 \mathrm{G}$. Magnetic field values were calibrated against a DPPH standard. The mw frequency was measured using a Marconi Instruments $2440 \mathrm{mw}$ counter.

Pulsed EPR spectroscopy was performed on a Bruker eleXsys E680 spectrometer fitted with a Bruker MD5-W1 resonator and equipped with an Oxford helium CF 935 flow cryostat. For LS samples spectra were measured at $10 \mathrm{~K}$ and for HS samples the temperature was lowered to $4 \mathrm{~K}$.

Field-Swept Echo (FSE) spectra: Samples were initially characterized by measurement of the FSE spectrum (the pulsed-EPR equivalent of a cw-EPR experiment) prior to more advanced pulsed experiments. A $\pi / 2-\tau-\pi-\tau$ pulse sequence is applied as the magnetic field is swept in order to obtain an EPR spectrum. 
Three-pulse Electron Spin Echo Envelope Modulation (ESEEM): The three-pulse ESEEM pulse sequence of $\pi / 2-\tau-\pi / 2-T-\pi / 2-\tau$ was applied in conjunction with ${ }^{15} \mathrm{~N}$ labeled nitrite to determine the hyperfine coupling from nitrite nitrogen in the LS complex.

Matched HYSCORE: matched-HYSCORE was applied in order to optimize nitrogen hyperfine couplings, it (15) incorporates matched pulses (16) into the standard HYSCORE sequence. A matched also known as a high-turning angle (HTA) pulse increases the efficiency of the forbidden transfers within the experiment in order to achieve larger signal intensities in both ESEEM (Electron Spin-Echo Envelope Modulation) and HYSCORE experiments. A $\pi / 2-\tau-$ $H T A-T_{1}-\pi-T_{2}-H T A-\tau$ pulse sequence was used with HTA pulses of 128 ns. The application of matched pulses to the HYSCORE experiment has been shown to increase the signal-to-noise ratio for strongly coupled nitrogens significantly. The sequence has also facilitated the application of the HYSCORE technique to $\mathrm{S}>1 / 2$ systems (17).

Hyperfine Sublevel Correlation (HYSCORE): The standard HYSCORE pulse sequence $\pi / 2-$ $\tau-\pi / 2-T_{1}-\pi-T_{2}-\pi / 2-\tau$ (140 ns $\tau$-value, $16 \mathrm{~ns} \pi / 2$ and $32 \mathrm{~ns} \pi$-pulse ) was used to examine the contribution to the $\mathrm{Mb}$ and $\mathrm{Mb}-\mathrm{NO}_{2} \mathrm{HYSCORE}$ spectrum from protons in the HS complex.

Simulation of EPR spectra: Spectra are simulated using the EasySpin (18) toolbox for Matlab.

\section{RESULTS}

Increase in $H S$ signal of $M b$ with addition of nitrite: The EPR spectra obtained for $2 \mathrm{mM} \mathrm{Mb}$ and $\mathrm{Mb}-\mathrm{NO}_{2}$ at $\mathrm{pH} 10.8$ are presented The spectrum of isolated $\mathrm{Mb}$ at $\mathrm{pH} 10.8$ (Fig. 2A), is dominated by a LS rhombic signal associated with the Mb-hydroxide complex (19). A very small contribution from a HS signal, attributable to aquomet-Mb, is also observed. Typical HS ( $\mathrm{S}=$ 5/2) heme EPR spectra are predominantly axial, having a low-field component at $\mathrm{g}_{\mathrm{x}, \mathrm{y}} \approx 6$ and components at $\mathrm{g}_{\mathrm{z}} \approx 2$. The addition of nitrite to the same sample (Fig.2B) led to the observation of an additional LS rhombic EPR signal with $\mathrm{g}$-values $\left[\mathrm{g}_{\mathrm{ZZ}} \approx 3.03, \mathrm{~g}_{\mathrm{YY}} \approx 2.2, \mathrm{~g}_{\mathrm{XX}} \approx 1.53\right.$ ] (following the axis assignment for LS Heme complexes of Walker (13) ) which are very comparable to those values observed previously for a Mb-nitrite complex (19). At this $\mathrm{pH}$ there is, however, still a contribution from Mb-hydroxide $\left[\mathrm{g}_{\mathrm{ZZ}} \approx 2.62, \mathrm{~g}_{\mathrm{YY}} \approx 2.18, \mathrm{~g}_{\mathrm{XX}} \approx 1.86\right]$..A closer examination of the HS EPR signal after addition of nitrite reveals an increase in intensity of the low-field component and a change of g-values from $\left[\mathrm{g}_{\mathrm{x}, \mathrm{y}} \approx 5.95, \mathrm{~g}_{\mathrm{z}} \approx 2.015\right]$ for the aquomet-Mb signal to $\left[\mathrm{g}_{\mathrm{x}, \mathrm{y}} \approx 5.99, \mathrm{~g}_{\mathrm{z}} \approx 2.00\right]$ after the addition of nitrite.

Quantification of species contribution from spectral simulation: samples of $250 \mu \mathrm{M} \mathrm{Mb}$ at 
EPR of Nitrite Binding in Myoglobin

each $\mathrm{pH}$ value were measured at $10 \mathrm{~K}$. Samples were then thawed, had nitrite added and were remeasured (Fig.3A-E). The spectra were then simulated using g-values for each species as indicated above. The change in the contribution to the spectra with the addition of nitrite were then plotted as a function of $\mathrm{pH}$ (Fig. 3F-G). At pH 6.5 and 7.5 Mb is initially found in a purely

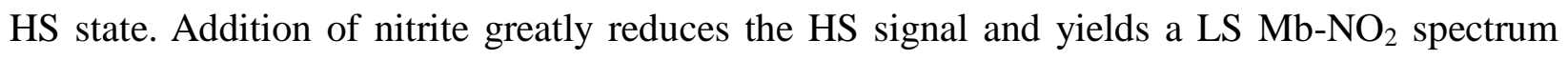
with g-values slightly different to those observed at $\mathrm{pH} 9.5$ and 10.8 ( $\left[\mathrm{g}_{\mathrm{ZZ}} \approx 3.0 \mathrm{~g}_{\mathrm{YY}} \approx 2.21 \mathrm{~g}_{\mathrm{XX}}\right.$ $\approx 1.56])$. At $\mathrm{pH} 8.5 \mathrm{Mb}$ is found in a predominantly HS state but with a LS. Nitrite addition also

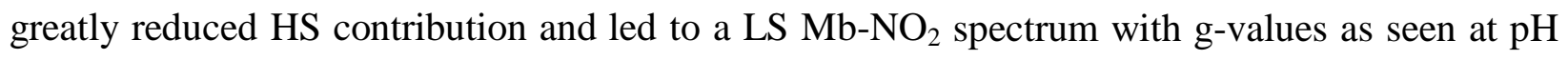
6.5 and 7.5. For pH 9.5 and $10.8 \mathrm{Mb}$ was predominantly in a LS form. An increase in HS EPR signal was found after nitrite was added as well as LS Mb-NO 2 and LS-Mb. At pH 10.8 the contribution to the spectrum from the HS signal increased approximately two-fold after nitrite addition.

Three-pulse ESEEM of ${ }^{15} \mathrm{~N}$ nitrite: The $10 \mathrm{~K}$ spectra of $2 \mathrm{mM}{ }^{14} \mathrm{~N}$ and ${ }^{15} \mathrm{~N} \mathrm{Mb}-\mathrm{NO}_{2} \mathrm{pH} 7.5$ (Fig.4a) measured at cannonical positions for the $\mathrm{LS}-\mathrm{NO}_{2}$ case, revealed spectral changes associated with an isotope effect only at the $\mathrm{g}_{\mathrm{z}}$-position. Simulation of the time and frequency domains of this position (Fig.4B) yielded the following parameters; [-0.05 -0.05 4.03] $\mathrm{MHz}$ hyperfine coupling and [-0.2475 -0.25025 0.5] MHz quadrupole couplings for the nitrite ${ }^{14} \mathrm{~N}$.

Matched-pulse HYSCORE: The matched-Pulse HYSCORE spectrum of LS Mb- ${ }^{14} \mathrm{NO}_{2}$ at $\mathrm{pH}$ 7.5 recorded at $10 \mathrm{~K}$ is shown (Fig 5). After Fourier Transformation of the two dimensional data set the figure consists of two quadrants, $[-,+]$ and $[+,+]$ which represent domains where strong $\left(A_{i s o}>2 v_{14 N}\right)$ and weak $\left(A_{i s o}<2 v_{14 N}\right)$ hyperfine couplings respectively are observed. In the $[-,+]$ quadrant peaks which are associated with the double-quantum (DQ) transitions of the directly coordinating heme and histidine (His93) nitrogens are observed. A contribution from the ${ }^{14} \mathrm{~N}$ of nitrite is apparent in the $[+,+]$ quadrant, whose magnitude is consistent with a nitrogen atom that is not directly coordinated to the Fe atom (20).

FSE of HS complexes: The 4 K FSE spectra of HS Mb and Mb-nitrite at pH 7.5, 9.5 and 10.8 measured, a ( $\tau$-value of $160 \mathrm{~ns}$ and $32 \mathrm{~ns} \pi$-pulse), are shown (Fig. 6A). For these spectra measured using pulsed-EPR the position of the low-field g-value appears at different positions for the samples examined. $\mathrm{Hs} \mathrm{Mb}$ and $\mathrm{Mb}$-nitrite at $\mathrm{pH} 7.5$ have a peak at around $\mathrm{g}=5.86$ whilst the Mb-nitrite samples at $\mathrm{pH} 9.5$ and 10.8 have this peak at a visibly lower g-value of 5.48. It may also be seen that the other spectral features are located at the same positions in each sample (e.g. the $g=2$ peak) which rules out a field-offset between the spectra being responsible for the g-value difference. 
EPR of Nitrite Binding in Myoglobin

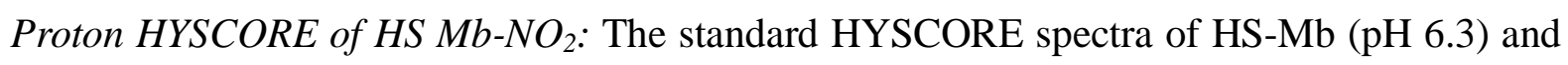
the HS contribution from Mb-nitrite ( $\mathrm{pH} 9.5$ ) (Fig 6B and 6C) were measured at $4 \mathrm{~K}$ at the $\mathrm{g}_{\mathrm{z}}{ }^{\text {eff }}$ position ( $3440 \mathrm{G})$. In the HS-Mb spectrum the correlation associated with a weakly coupled proton is seen centered at the proton Larmor frequency $(\sim 14.65 \mathrm{MHz})$. this correlation has been previously reported and assigned to the protons of a coordinated water molecule with a hyperfine coupling at this position of $\sim 5.9 \mathrm{MHz}(20)$, this value also agreed with the seminal single-crystal ENDOR study of Scholes (21). The figure also shows the HYSCORE spectrum of Mb-nitrite at pH 9.5 measured with the same experimental parameters and conditions that favor the measurement of the HS signal. The spectrum was also measured at the $\mathrm{g}_{\mathrm{z}}^{\text {eff }}$ position. In this spectrum proton contributions are absent suggesting that the HS species does not have a coordinated water or even hydroxide molecule.

\section{DISCUSSION}

Increased HS-signal with nitrite addition: The observed increase in the HS contribution at high $\mathrm{pH}$ is unlikely to be due to a coordinated water complex since the $\mathrm{pk}_{\mathrm{a}}$ of water coordinated to ferric $\mathrm{Mb}$ is known to be 8.9 (22). Above this $\mathrm{pH}$ the aquo-ligand is more likely to be deprotonated which results in a LS EPR signal. Interestingly a similar study of nitrite binding in hemoglobin $(\mathrm{Hb})$ has revealed significant $\mathrm{HS}$ signals at high $\mathrm{pH}$ although the origin of these signals was not discussed (23). Richter-Addo et al's findings suggested that the O-bound mode was facilitated by hydrogen bonding residues in the heme binding pocket, the most significant residue being His64. The $\mathrm{pK}_{\mathrm{a}}$ of His64 is 4.4 (24), and is unlikely to be protonated above $\mathrm{pH} 8$. One possible explanation for the increased HS signal, observable above $\mathrm{pH}$ 8.5,could be the presence of the $N$-nitro mode; hence the LS signal associated with the addition of nitrite would therefore be due to the $O$-nitrito form. In principle pulsed EPR spectroscopy allows the observation of weak hyperfine interactions that are masked in the broad cw-EPR spectrum to be resolved (25). Pulsed-hyperfine EPR spectroscopy in particular, can provide a detailed insight into the interactions of nearby magnetic nuclei with a paramagnetic centre.

Examination of LS nitrite complex: Three-pulse Electron-Spin Echo Envelope Modulation (ESEEM) spectroscopy (26) was employed in conjunction with ${ }^{15} \mathrm{~N}$ isotope labeled nitrite to observe the existence of a hyperfine contribution from the nitrite nitrogen atom in the LS case. An accurate determination of the complete ${ }^{14} \mathrm{~N} /{ }^{15} \mathrm{~N}$ hyperfine interaction allows the distinction between the two possible modes of nitrite binding. Both time and frequency-domain spectra of Mb-nitrite (at pH 7.5) are depicted (Fig. 4A). In the time domain spectra (left) a clear effect of 
isotope substitution is observed when the field position chosen for the ESEEM experiment is aligned along the $\mathrm{g}_{\mathrm{ZZ}}$ component of the LS heme signal. An apparent oscillation is now present which results, after Fourier Transformation, in an intense peak at $\approx 1.5 \mathrm{MHz}$ (right, top trace). A spectral simulation of these spectra yielded the following parameters; [-0.05 -0.05 4.03] $\mathrm{MHz}$ hyperfine coupling and $[-0.2475-0.250250 .5] \mathrm{MHz}$ quadrupole couplings for the nitrite ${ }^{14} \mathrm{~N}$. The magnitude of this ${ }^{14} \mathrm{~N}$ hyperfine coupling is rather small and not typical of a directly coordinated $\mathrm{N}$-atom. A large hyperfine coupling constant is expected for a directly coordinated nitrogen atom. In order to resolve the observed nuclear hyperfine interactions further HYSCORE spectroscopy (27) was employed. A standard HYSCORE pulsed sequence employed along the gzz orientation was poorly resolved, hence matched-pulse HYSCORE was employed. The observation of the nitrite nitrogen coupling peak being present in the $[+,+]$ quadrant was indicative of a indirectly coordinated atom. This assignment supports the interpretation of the LS species being $O$-bound to nitrite.

Investigation of HS signal: Pulsed-EPR was also applied to investigate the HS species formed after addition of nitrite. In order to obtain the FSE spectra of $\mathrm{Mb}(\mathrm{pH}$ 6.5) and Mb-nitrite (at pH 7.5, 9.5 and 10.8) (Fig. 6A), a temperature of < $4 \mathrm{~K}$ was required. Contributions from any LS species were suppressed further by optimizing the microwave power used in the Hahn-echo sequence for these HS species. The two panels on the right (Fig 6B and 6C) also present the ${ }^{1} \mathrm{H}-$ region of the respective HYSCORE spectra recorded at the $\mathrm{g}_{\mathrm{zZ}}$-position for $\mathrm{Mb}$ at $\mathrm{pH} 6.5$ and Mb-nitrite at $\mathrm{pH}$ 9.5. The same pulse-lengths and distances were the same as used in the FSE spectra. The top two spectra (Fig. 6A) are recorded at low pH and reflect either a purely HS-Mb state (aquomet $\mathrm{Mb}$ ) or this state in the presence of nitrite and where it is expected that a water molecule is coordinated to the iron center. HYSCORE spectra recorded at $g_{\text {eff }}(g \sim 2)$ reveal a correlation centered at the proton Larmor frequency. The bottom spectra are Mb samples in the presence of nitrite at higher $\mathrm{pH}(9.5-10.8)$ where the novel HS species is observed. The respective HYSCORE spectra (Fig. 5C) indicate that under these conditions no ${ }^{1} \mathrm{H}$ correlations are observed, which would suggest that this is a new HS species formed by the addition of nitrite, as it does not contain a bound water molecule as found for HS-Mb. It is proposed that this species arises from an $N$-nitrito HS-Mb species, although the presence of a spin-equilibrium cannot be ruled out. In addition, as with the CW-EPR spectra there is also a measurable variation in the g-value of the lower field features of these two states from a g-value of 5.48 (at both $\mathrm{pH}$ 10.8 and 9.5) to a g-value of 5.86 at low $\mathrm{pH}$. The difference is more marked in pulsed EPR however, due to tau-value enhancement by the filed-swept echo. These results clearly suggest 
EPR of Nitrite Binding in Myoglobin

that this new HS species observed at high $\mathrm{pH}$ is not due to coordinated water or hydroxide and is therefore likely to be due to coordinated N-bound nitrite. Indeed, in a recent publication density functional theory suggested both nitrite forms to be energetically favorable (28).

There is evidence that the dynamics of hydrogen-bonding may be related to enzymatic activity in at least one other heme protein (29) and hydrogen-bonding is responsible for differing oxygen binding energies in $\mathrm{Mb}$ and $\mathrm{Hb}$ from different species (30). It is therefore likely that any nitrite reductase activity of $\mathrm{Mb}$ may be facilitated by differential ligation of the ion to the heme center controlled via hydrogen bonding.

\section{REFERENCES}

1. Cosby, K., Partovi, K. S., Crawford, J. H., Patel, R. P., Reiter, C. D., Martyr, S., Yang, B. K., Waclawiw, M. A., Zalos, G., Xu, X. L., Huang, K. T., Shields, H., Kim-Shapiro, D. B., Schechter, A. N., Cannon, R. O., and Gladwin, M. T. (2003) Nitrite reduction to nitric oxide by deoxyhemoglobin vasodilates the human circulation. Nature Medicine 9, 14981505

2. Bredt, D. S., Hwang, P. M., Glatt, C. E., Lowenstein, C., Reed, R. R., and Snyder, S. H. (1991) Cloned and Expressed Nitric-Oxide Synthase Structurally Resembles Cytochrome-P-450 Reductase. Nature 351, 714-718

3. Zweier, J. L., Wang, P. H., Samouilov, A., and Kuppusamy, P. (1995) EnzymeIndependant Formation of Nitric-Oxide in Biological Tissues. Nature Medicine 1, 804809

4. Lauer, T., Preik, M., Rassaf, T., Strauer, B. E., Deussen, A., Feelisch, M., and Kelm, M. (2001) Plasma nitrite rather than nitrate reflects regional endothelial nitric oxide synthase activity but lacks intrinsic vasodilator action. Proc. Natl. Acad. Sci. U. S. A. 98, 1281412819

5. Copeland, D. M., Soares, A. S., West, A. H., and Richter-Addo, G. B. (2006) Crystal structures of the nitrite and nitric oxide complexes of horse heart myoglobin. J. Inorg. Biochem. 100, 1413-1425

6. Hitchman, M. A., and Rowbottom, G. L. (1982) Transition-Metal Nitrite Complexes. 
EPR of Nitrite Binding in Myoglobin

\section{Coordination Chemistry Reviews 42, 55-132}

7. Einsle, O., Messerschmidt, A., Huber, R., Kroneck, P. M. H., and Neese, F. (2002) Mechanism of the six-electron reduction of nitrite to ammonia by cytochrome c nitrite reductase. Journal of the American Chemical Society 124, 11737-11745

8. Williams, P. A., Fulop, V., Garman, E. F., Saunders, N. F. W., Ferguson, S. J., and Hajdu, J. (1997) Haem-ligand switching during catalysis in crystals of a nitrogen-cycle enzyme. Nature 389, 406-412

9. Crane, B. R., Siegel, L. M., and Getzoff, E. D. (1997) Probing the catalytic mechanism of sulfite reductase by x-ray crystallography: Structures of the Escherichia coli hemoprotein in complex with substrates, inhibitors, intermediates, and products. Biochemistry 36, 12120-12137

10. Wyllie, G. R. A., and Scheidt, W. R. (2002) Solid-state structures of metalloporphyrin NOx compounds. Chemical Reviews 102, 1067-1089

11. Nasri, H., Ellison, M. K., Shang, M. Y., Schulz, C. E., and Scheidt, W. R. (2004) Variable pi-bonding in iron(II) porphyrinates with nitrite, $\mathrm{CO}$, and tert-butyl isocyanide: Characterization of [Fe(TpivPP)(NO2)(CO)](-). Inorg. Chem. 43, 2932-2942

12. Yi, J., Heinecke, J., Tan, H., Ford, P. C., and Richter-Addo, G. B. (2009) The Distal Pocket Histidine Residue in Horse Heart Myoglobin Directs the O-Binding Mode of Nitrite to the Heme Iron. Journal of the American Chemical Society 131, 18119-18128

13. Walker, F. A. (1999) Magnetic spectroscopic (EPR, ESEEM, Mossbauer, MCD and NMR) studies of low-spin ferriheme centers and their corresponding heme proteins. Coordination Chemistry Reviews 185-186, 471-534

14. Williams-Smith, D. L., Bray, R. C., Barber, M. J., Tsopanakis, A. D., and Vincent, S. P. (1977) Changes in Apparent $\mathrm{pH}$ on Freezing Aqueous Buffer Solutions and Their Relevance to Biochemical EPR Spectroscopy. Biochemical Journal 167, 593-600

15. Jeschke, G., Rakhmatullin, R., and Schweiger, A. (1998) Sensitivity enhancement by matched microwave pulses in one- and two-dimensional electron spin echo envelope modulation spectroscopy. Journal of Magnetic Resonance 131, 261-271

16. Jeschke, G., and Schweiger, A. (1996) Matched two-pulse electron spin echo envelope modulation spectroscopy. J. Chem. Phys. 105, 2199-2211

17. Fittipaldi, M., Garcia-Rubio, I., Trandafir, F., Gromov, I., Schweiger, A., Bouwen, A., and Van Doorslaer, S. (2008) A multi-frequency pulse EPR and ENDOR approach to study strongly coupled nuclei in frozen solutions of high-spin ferric heme proteins. Journal of 
EPR of Nitrite Binding in Myoglobin

Physical Chemistry B 112, 3859-3870

18. Stoll, S., and Schweiger, A. (2006) EasySpin, a comprehensive software package for spectral simulation and analysis in EPR. Journal of Magnetic Resonance 178, 42-55

19. Sono, M., and Dawson, J. H. (1982) Formation of low spin complexes of ferric cytochrome P-450-CAM with anionic ligands. Spin state and ligand affinity comparison to myoglobin. J. Biol. Chem. 257, 5496-5502

20. Garcia-Rubio, I., Fittipaldi, M., Trandafir, F., and Van Doorslaer, S. (2008) A Multifrequency HYSCORE Study of Weakly Coupled Nuclei in Frozen Solutions of High-Spin Aquometmyoglobin. Inorg. Chem. 47, 11294-11304

21. Scholes, C. P., Lapidot, A., Mascarenhas, R., Inubushi, T., Isaacson, R. A., and Feher, G. (1982) Electron Nuclear Double-Resonance (ENDOR) from Heme and Histidine Nitrogens in Single-Crystals of Aquometmyoglobin. Journal of the American Chemical Society 104, 2724-2735

22. Lin, J., Merryweather, J., Vitello, L. B., and Erman, J. E. (1999) Metmyoglobin/Azide: The Effect of Heme-Linked Ionizations on the Rate of Complex Formation. Archives of Biochemistry and Biophysics 362, 148-158

23. Schwab, D. E., Stamler, J. S., and Singel, D. J. (2010) EPR Spectroscopy of Nitrite Complexes of Methemoglobin. Inorg. Chem. 49, 6330-6337

24. Yang, F., and Phillips Jr, G. N. (1996) Crystal Structures of CO-, Deoxy- and Metmyoglobins at Various pH Values. J. Mol. Biol. 256, 762-774

25. Prisner, T., Rohrer, M., and MacMillan, F. (2001) Pulsed EPR Spectroscopy: Biological Applications. Annual Review of Physical Chemistry 52, 279-313

26. Deligiannakis, Y., Louloudi, M., and Hadjiliadis, N. (2000) Electron spin echo envelope modulation (ESEEM) spectroscopy as a tool to investigate the coordination environment of metal centers. Coordination Chemistry Reviews 204, 1-112

27. Hofer, P., Grupp, A., Nebenfuhr, H., and Mehring, M. (1986) Hyperfine Sublevel Correlation (HYSCORE) Spectroscopy - A 2D Electron-Spin-Resonance Investigation of the Squaric Acid Radical. Chemical Physics Letters 132, 279-282

28. Silaghi-Dumitrescu, R., Svistunenko, D. A., Cioloboc, D., Bischin, C., Scurtu, F., \& Cooper, C. E. (2014). Nitrite binding to globins: linkage isomerism, EPR silence and reductive chemistry. Nitric Oxide, 42, 32-39.

29. Radoul, M., Bykov, D., Rinaldo, S., Cutruzzolà, F., Neese, F., and Goldfarb, D. (2011) Dynamic Hydrogen-Bonding Network in the Distal Pocket of the Nitrosyl Complex of 
EPR of Nitrite Binding in Myoglobin

Pseudomonas aeruginosa cd1 Nitrite Reductase. Journal of the American Chemical Society 133, 3043-3055

30. Kitagawa, T., Ondrias, M. R., Rousseau, D. L., Ikeda-Saito, M., and Yonetani, T. (1982) Evidence for hydrogen bonding of bound dioxygen to the distal histidine of oxycobalt myoglobin and haemoglobin. Nature 298, 869-871

\section{FOOTNOTES}

*This work was financially supported by The Royal Society. FM is a Royal Society Wolfson Research Merit Award holder. EPSRC is also thanked for funding a PhD studentship.

${ }^{3}$ The abbreviations used are: EPR, Electron Paramagnetic Resonance; Mb, Myoglobin; Hb, Hemoglobin; NiR, Nitrite Reductase; LS, Low-Spin; HS, High-Spin; CW, Continuous-Wave; ESEEM, Electron-Spin Echo Envelope Modulation; HYSCORE, Hyperfine Sublevel Correlation; DQ, Double-Quantum.

\section{FIGURE LEGENDS}

Figure 1. Heme center from crystal structures of $\mathrm{Mb}$ with ligated nitrite anion. (2FRF; native Mb, 3HEP; Mb with H64V mutation and 3HEO; Mb with H64V and V67R mutation). Structures demonstrate $O$-nitrito (2FRF and $3 \mathrm{HEO}$ ) and $N$-nitro (3HEP) binding modes.

Figure 2. $10 \mathrm{~K}$ EPR spectra of $2 \mathrm{mM} \mathrm{Mb}$ in CAPS buffer (pH 10.8) before and after the addition of 240-fold molar excess nitrite (top and bottom respectively). g-values of each species indicated.

Figure 3. CW-EPR spectra (black) and simulations (red) measured at $10 \mathrm{~K}$ of $250 \mu \mathrm{M} \mathrm{Mb}$ before and after addition of 240-fold molar excess of nitrite (A - E) at pH 6.5, 7.5, 8.5, 9.5 and 10.8. Change in contribution from each species as determined from simulation ( $F$ and $\mathrm{G})$. Plot $\mathrm{G}$ is as plot $\mathrm{F}$ but with the $\mathrm{HS}-\mathrm{Mb}$ contribution removed to more clearly show the contributions from the other species. 
Figure 4. Time-domain and frequency-domain (A and B) three-Pulse ESEEM spectra of Mb${ }^{14} \mathrm{NO}_{2}$ and $\mathrm{Mb}-{ }^{15} \mathrm{NO}_{2}$ (Solid and dotted lines) measured at canonical positions. Spectra measured at $10 \mathrm{~K}$.

Figure 5. Matched-pulse HYSCORE of $2 \mathrm{mM} \mathrm{Mb}-\mathrm{NO}_{2}(\mathrm{pH} 7.5)$ measured at $10 \mathrm{~K}$. Contribution to spectrum from the nitrite nitrogen is circled with a dashed line in the $[+,+]$ quadrant.

Figure 6. FSE spectra of a series of $\mathrm{Mb}$ and $\mathrm{Mb}-\mathrm{NO}_{2}$ complexes as indicated (A). HYSCORE spectra of $\mathrm{Mb}$ at $\mathrm{pH} 6.5$ (B) and $\mathrm{Mb}-\mathrm{NO}_{2} \mathrm{pH} 9.5$ (B). Spectra measured at 4K. (B) shows the contribution of proton couplings absent in (C). 
bioRxiv preprint doi: https://doi.org/10.1101/252775; this version posted January 24, 2018. The copyright holder for this preprint (which was not certified by peer review) is the author/funder, who has granted bioRxiv a license to display the preprint in perpetuity. It is made available under aCC-BY-NC-ND 4.0 International license.

\section{Figure 1}

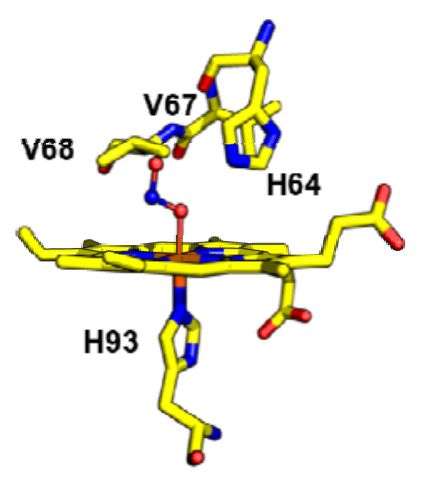

2FRF

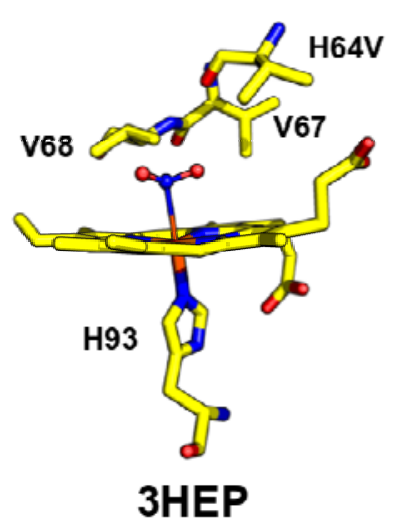

3HEP

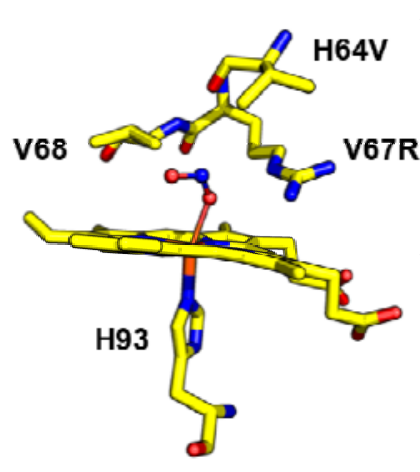

3HEO 
bioRxiv preprint doi: https://doi.org/10.1101/252775; this version posted January 24, 2018. The copyright holder for this preprint (which was not certified by peer review) is the author/funder, who has granted bioRxiv a license to display the preprint in perpetuity. It is made available under aCC-BY-NC-ND 4.0 International license.

EPR of Nitrite Binding in Myoglobin

\section{Figure 2}

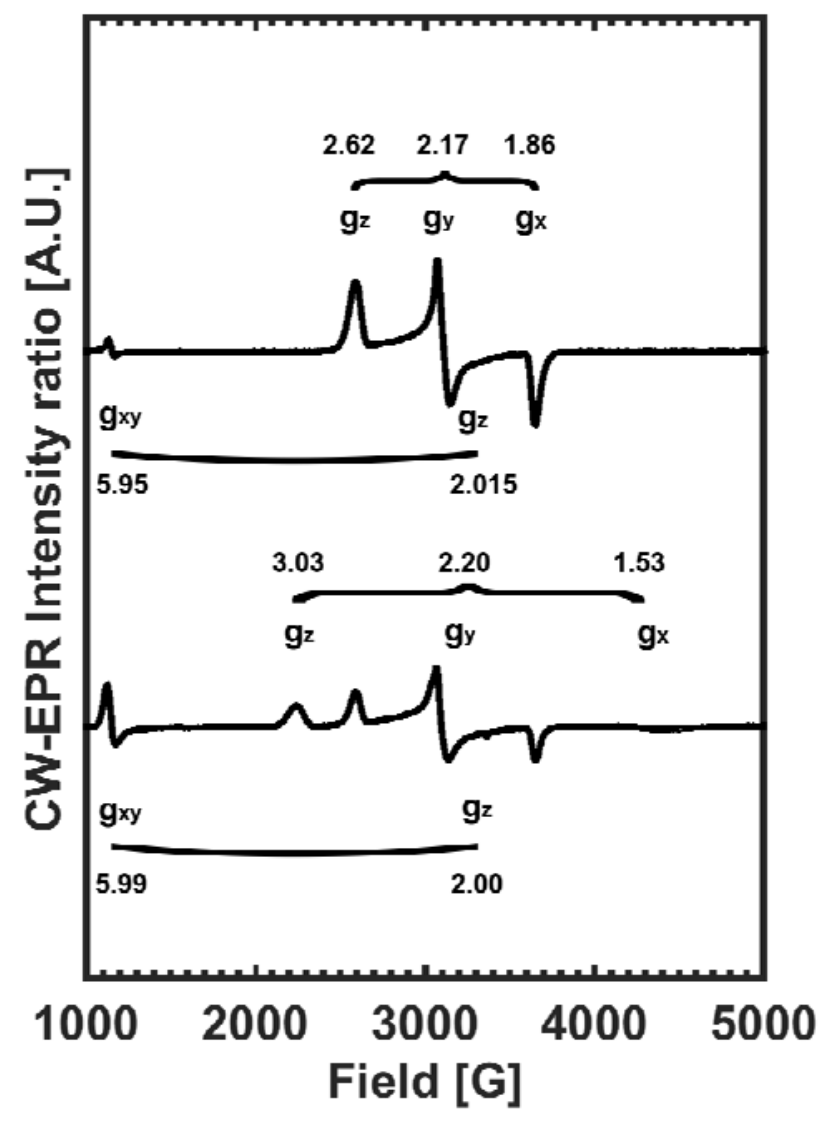


bioRxiv preprint doi: https://doi.org/10.1101/252775; this version posted January 24, 2018. The copyright holder for this preprint (which was not certified by peer review) is the author/funder, who has granted bioRxiv a license to display the preprint in perpetuity. It is made available under aCC-BY-NC-ND 4.0 International license.

Figure 3
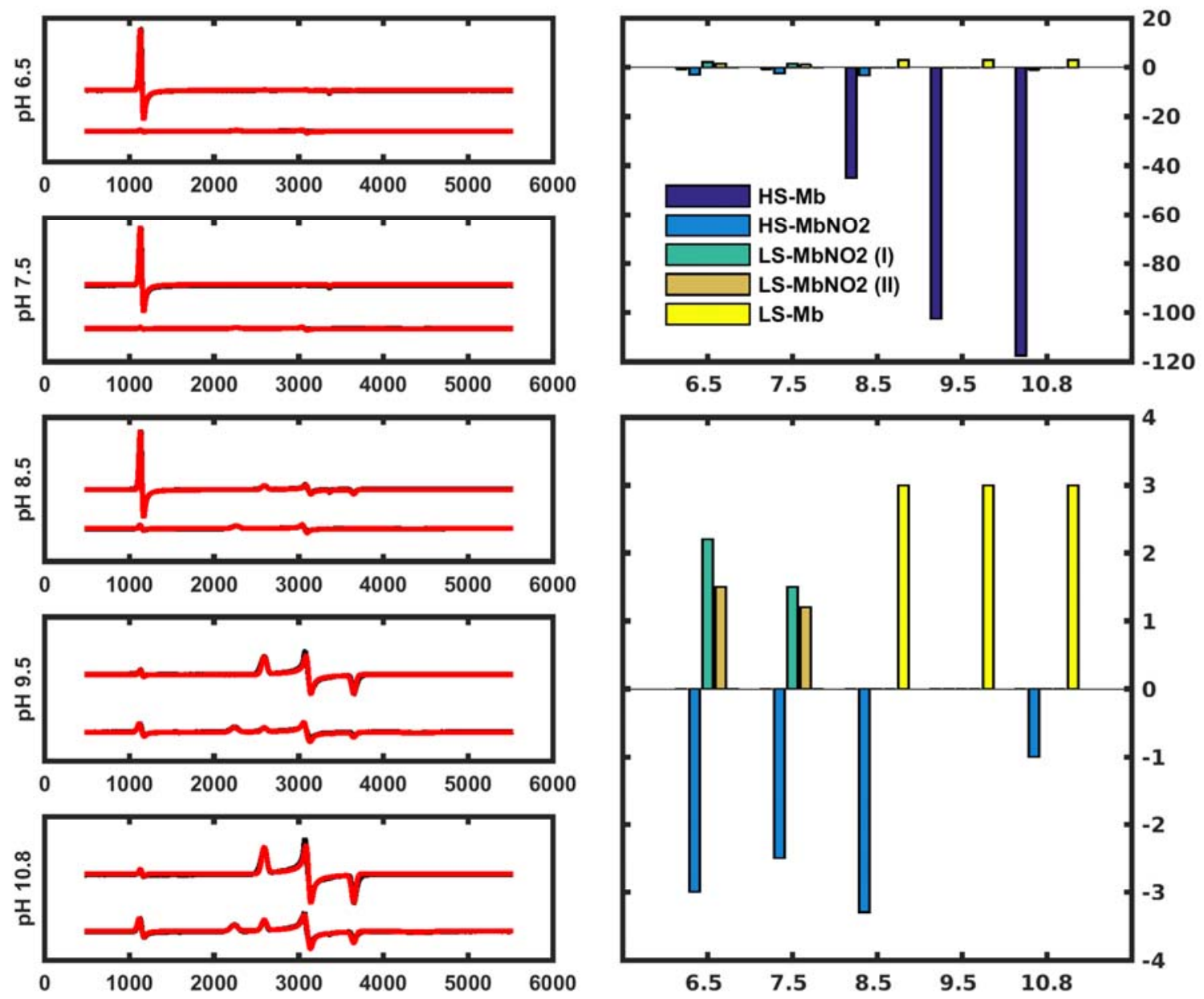
bioRxiv preprint doi: https://doi.org/10.1101/252775; this version posted January 24, 2018. The copyright holder for this preprint (which was not certified by peer review) is the author/funder, who has granted bioRxiv a license to display the preprint in perpetuity. It is made available under aCC-BY-NC-ND 4.0 International license.

EPR of Nitrite Binding in Myoglobin

\section{Figure 4}
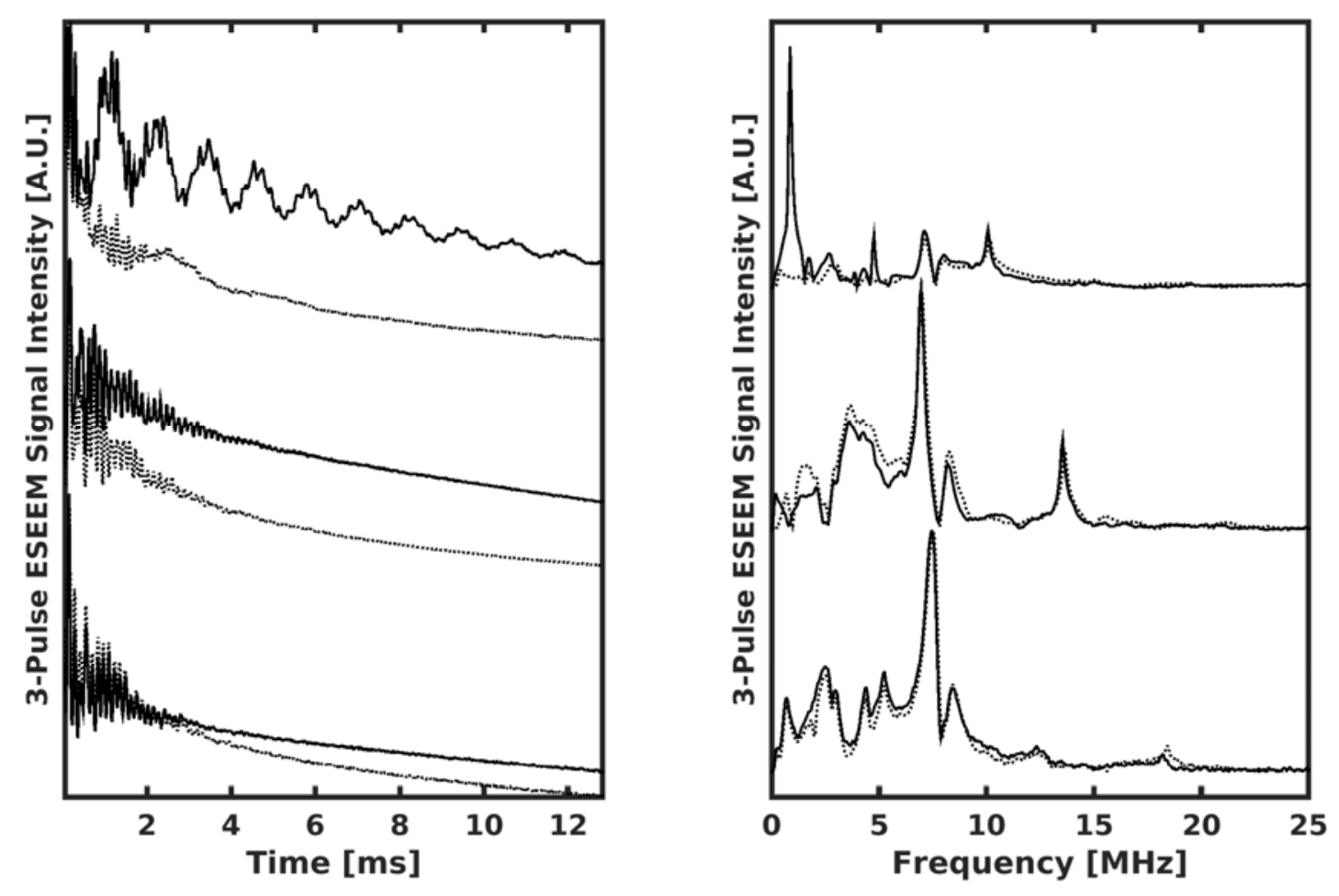
bioRxiv preprint doi: https://doi.org/10.1101/252775; this version posted January 24, 2018. The copyright holder for this preprint (which was not certified by peer review) is the author/funder, who has granted bioRxiv a license to display the preprint in perpetuity. It is made available under aCC-BY-NC-ND 4.0 International license.

EPR of Nitrite Binding in Myoglobin

\section{Figure 5}

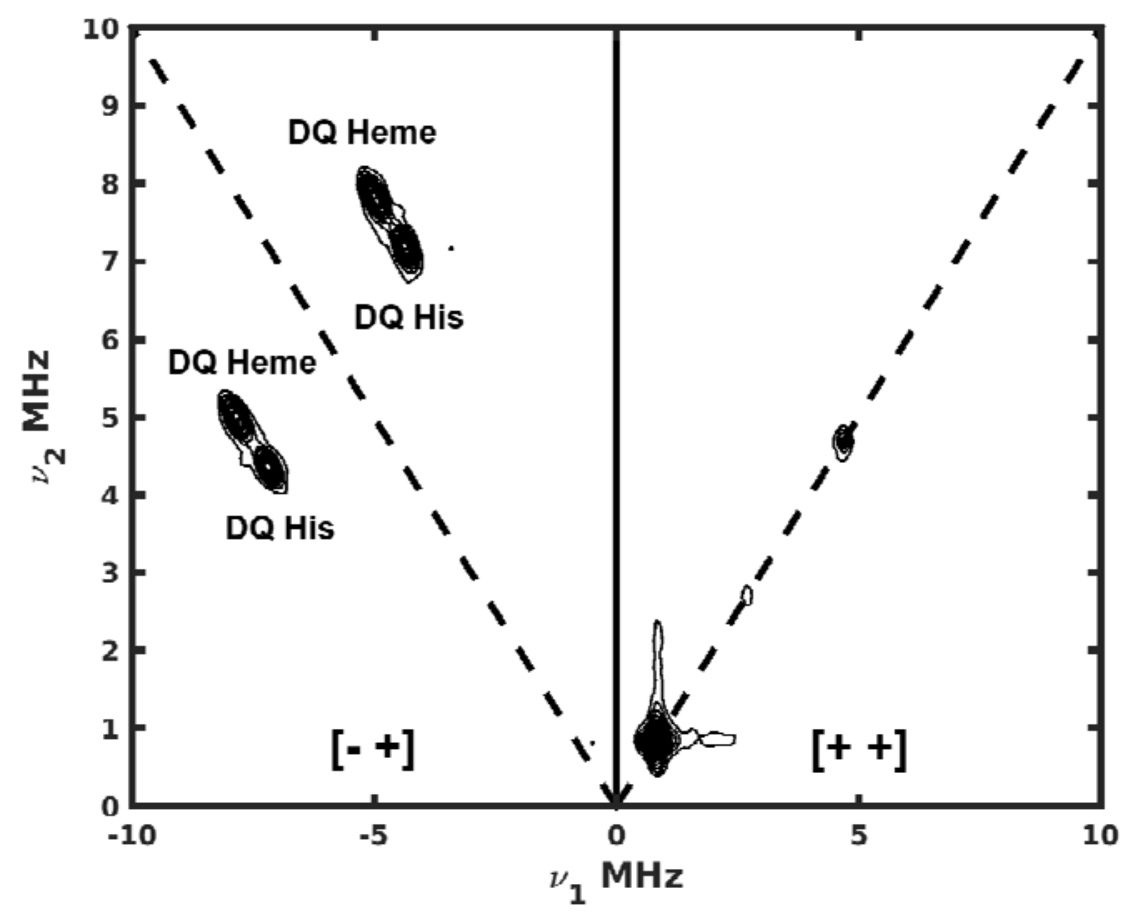


bioRxiv preprint doi: https://doi.org/10.1101/252775; this version posted January 24,2018 . The copyright holder for this preprint (which was not certified by peer review) is the author/funder, who has granted bioRxiv a license to display the preprint in perpetuity. It is made available under aCC-BY-NC-ND 4.0 International license.
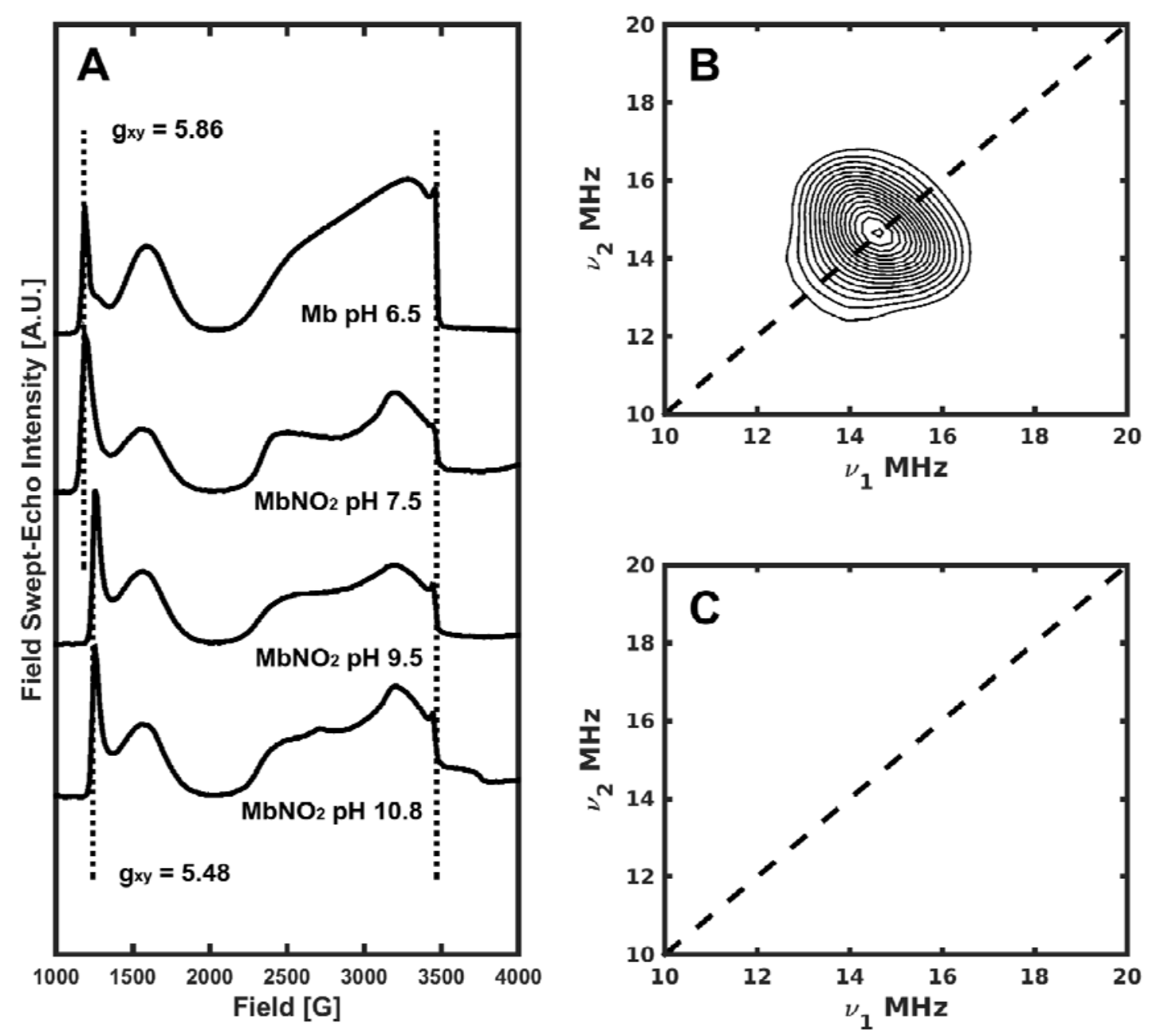

Figure 6 